This is a pre-copyedited, author-produced version of an article accepted for publication in Science and Public Policy following peer review. The version of record Fabiano, Gianluca, Marcellusi, Andrea and Favato, Giampiero (2020) Channels and processes of knowledge transfer : how does knowledge move between university and industry? Science and Public Policy, 47(2), pp. 256-270 is available online at:

https://doi.org/10.1093/scipol/scaa002 


\title{
Channels and processes of knowledge transfer: how does knowledge move between university and industry?
}

\begin{abstract}
:
The role of knowledge and technology transfer between academia and the industry has received increasing attention in the analysis of innovation. This paper aims to explore the scientific literature concerning knowledge transport mechanisms and describe how the topic was organized by previous studies and terminologies applied. A systematic review was conducted in which the content of recent contributions best fitting these intensions was analysed. The characteristics of knowledge, individuals, organizations and disciplines were found to be the main determinants in the adoption of transfer mechanisms. These were classified in terms of formalization, relational involvement, direction and time. On the revealed multi-dimensionality of knowledge transfer and complementarity between transfer activities we framed a new taxonomy distinguishing between channels and processes. Future research may deepen these factors, such as the economic aspects driving the adoption of transfer mechanisms informing decisions on the funding of innovation.
\end{abstract}

\section{Introduction:}

Universities are recognized as unique actors in the production and delivery of new knowledge to support economic development (Salter and Martin, 2001; Mansfield, 1991; Pavitt, 1991; Rosenberg and Nelson, 1994). Besides teaching and research, academia engages in a 'third mission' through knowledge and technology transfer activities (Etzkowitz and Leydesdorff, 2000; Leydesdorff and Etzkowitz, 1996; 1998; 1997). Within the 'triple helix' of university-industry-government interaction (Etzkowitz and Leydesdorff, 2000), universities act as ambidextrous organizations that pursue research excellence but also promote commercialization (Chang, Yang and Chen, 2009). In this context, knowledge transfer involves social convention and legal rights, as well as economic interests and includes activities which enable the transfer of implicit knowledge, codified or non-codified know-how, and technology into use (Bercovitz and Feldman, 2006).

The closeness in the implied meanings of knowledge and technology and in the way these are transferred, shared, learnt and applied by individuals and organizations, have led the terms 'technology' and 'knowledge' (KT) to be used interchangeably in many studies (Gopalakrishnan and Santoro, 2004). (Roessner, 2000) define KT transfers as the "movement of know-how, technical knowledge, or technology from one organizational setting to another". (Bozeman, 2000) argued that when a technological product is transferred, the knowledge upon which this is based is also diffused. (Gopalakrishnan and Santoro, 2004) contend that technology transfer embodies tools for changing the environment whereas knowledge is more directed towards the 'why' for change. (Battistella, De Toni and Pillon, 2016) point out the concept of 'know-how' have become a binding between knowledge and technology.

The literature on the subject is voluminous, extensive and varied in perspectives. Since technology and knowledge are intertwined, authors have made little attempt to draw a line to differentiate asserting that these concepts are inseparable. Furthermore, research on university-industry (U-I) knowledge and technology transfer have been investigated through various 'channels' (Cohen, Nelson and Walsh, 2002; D'Este and Patel, 2007; Faulkner and Senker, 1994); 'mechanisms' (MeyerKrahmer and Schmoch, 1998); 'interaction modes' (Grimpe and Hussinger, 2008); 'links' (Perkmann 
and Walsh, 2007); 'knowledge interactions' (Schartinger, Rammer and Fröhlich, 2006) that function as informational or social pathways through which knowledge, technologies and other resources are exchanged or co-produced across the academia and the industry.

In this context, relatively few studies propose a framework to highlight the main parameters and levers on the adoption of different channels of technology/knowledge transfer. In particular published literatures seem failing disentangling the actual knowledge transport mechanisms.

Therefore, in this paper we propose a literature review that helps in converging on shared elements of knowledge transfer mechanisms and on a framework useful for future research.

The purpose of this paper is to gain a better understanding of academia-industry interactions and to explore the conduit of knowledge transfer to bring innovation to market.

The main research questions guiding our review is: what determine the movement of knowledge between university and industry? And, what are the characteristics of the transport mechanism?

To answer these questions, we build upon a number of studies exploring the characteristics of knowledge, individuals, organizations and disciplines and we classify KT transfers in terms of grades of formalization, relational involvement, direction and time.

For our purposes, we do not attempt to treat knowledge and technology as distinct entities but we rather consider the different features of knowledge (including the concept of knowledge as a tool) in the choice for the modes through which multiple actors adopt and shape the knowledge content for different purposes. Given that, the nature of knowledge and the relational context of sources and recipients involved in the transfer activities are treated here with the specific view of individuating what drives the adoption of different transfer modes and the way science can be transferred.

Doing so, our work contributes to existing research in several specific ways. First, being our review centred exclusively on the ways of knowledge transfer, the complex of inter-relational features involving university-industry collaborations is revised and employed with a peculiar aim: understanding how different transfer mechanisms coexists and the reasons for their adoption. Secondly, we synthesize our results in a novel taxonomy and we build on that a conceptual framework to facilitate the convergence towards a shared vision. Third, university-industry linkages have become imperative in the political agenda as a means to foster technology transfer and to improve the commercialization of university research as a key driver of national competitiveness. Therefore in our discussion we attempt to highlight some uncovered issues relevant both for future researches and to inform knowledge-based policies.

The remainder of the paper is organised as follows. Section 2 illustrates the methodological approach we adopted to identify and reduce relevant literature. Section 3 and 4 presents our descriptive and thematic analysis. In Section 5 we discuss our results and make the attempt to develop a new taxonomy and suggest directions for future research.

\section{Methodology:}

A systematic literature review was performed to establish the state of the current knowledge based on the available evidence. Systematic reviews are increasingly being adopted in the social sciences as they reduce subjective bias and risks of overlooking relevant literature (Burrows, 2000). In this article, we adopted and combined the guidelines suggested by (Tranfield, Denyer and Smart, 2003). Our objective was operationalized based on the approach followed by (Di Maddaloni and Davis, 2017), figure 1. 
Figure 1: Organising framework.

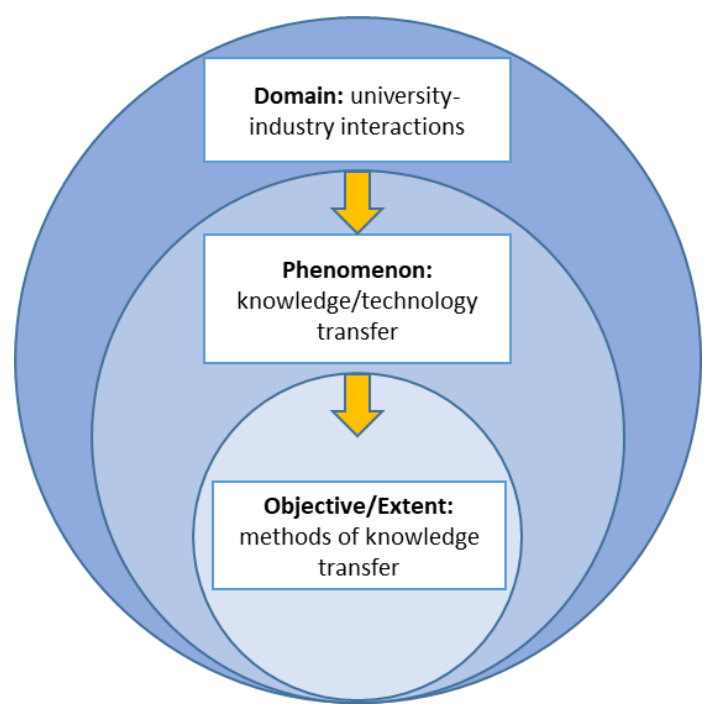

The topic was investigated with the aim of showing the potential connections within published literatures. Specifically, the streams of literature represented by the three levels of knowledge helped covering the research gap as a result of the following search procedure. In figure 2 we present the summarised retrieval process. This was further broke down in appendix $A$ in which we report the PRISMA chart developed by (Moher et al., 2009) which consists of a set of items for reporting in systematic reviews and meta-analyses.

\subsection{Keywords selection:}

The first step was to identify a list of keywords relevant to each area of investigation. These were refined through an ongoing discussion with senior academics and subsequently search strings were developed with the help of the Boolean operators. We also used the truncation symbol which allowed all ending variation to be searched (Vick and Robertson, 2017). Specifically, based on our organizing framework, the following search strings were employed in the current review: 1) Domain: ((research OR science OR intellectual OR discover* OR invent*); 2) Phenomenon: ((universit* OR academ) AND (industry)) AND (interact* OR engag* OR relat* OR collab*)) AND; 3) Extent: ((knowledge OR technology) AND (transfer* OR link* OR channel* OR mechanism*))), (see Appendix A for the string used as keyword search).

Studying the mechanisms of knowledge and technology transfer can be a way of gaining new perspectives on possible directions and approaches for research. However, this does not necessarily imply that innovation occurs (Vick and Robertson, 2017). For that reason, the keyword 'innovation' and its derivatives were not used.

\subsection{Selection criteria:}

Secondly, we conducted an extensive search in the titles, abstracts and author keywords of published, peer-reviewed articles held by the ISI Web of Science (WOS) databases between 1980 and 2018. Only articles written in English were included; proceeding papers, editorial material and reprints were excluded. The search was conducted in October 2018. The above procedure yielded 2,288 results. 


\subsection{Quality appraisal:}

Subsequently a two-stage quality assessment screening was performed. Following (Crossan and Apaydin, 2010), we first identified 511 high impact publications, which had at least 5 citations per year (using 2018 as the base year). Citation-based analysis is indeed recognised as a measure of the paper quality and a vote for its contribution towards knowledge (Saha, Saint and Christakis, 2003). Then, we recognized that citation based methods may discriminate against recent publications and hence we formed an additional group from the most recent publications made between 2016 and 2018. Based on the premise that top journals usually publish quality papers, we relied on the CABS journal guide to identify the most highly ranked journals on innovation and business and management (see Appendix A) and recent papers were included accordingly (174 publications). Duplicates resulting from both quality screening strategies were then removed. This procedure left us with a total of 379 articles.

\subsection{Content analysis:}

The content analysis used for paper selection represented a structured and systematic technique to identify the current body of knowledge and observe emerging patterns in the literature (Mok, Shen and Yang, 2015). Title and abstracts were read and selected based on deductively formed themes with specific reference to 'university-industry relations', 'KT activities', 'methods of knowledge transfer' used as keywords. We did not take in consideration articles which were focused exclusively on the technological aspects of knowledge. As a further criterion of delimitation, we chose to limit our analysis to publications which investigate the interaction between channels conceptually. Articles that take the perspective of a single channel were not included in the analysis.

Two investigators performed a blind reading of the materials, and any disagreement and risk of bias were solved through a discussion between the two review authors. As a result, 46 publications were included accordingly to our research questions (Appendix A).

Figure 2: Publications retrieval process

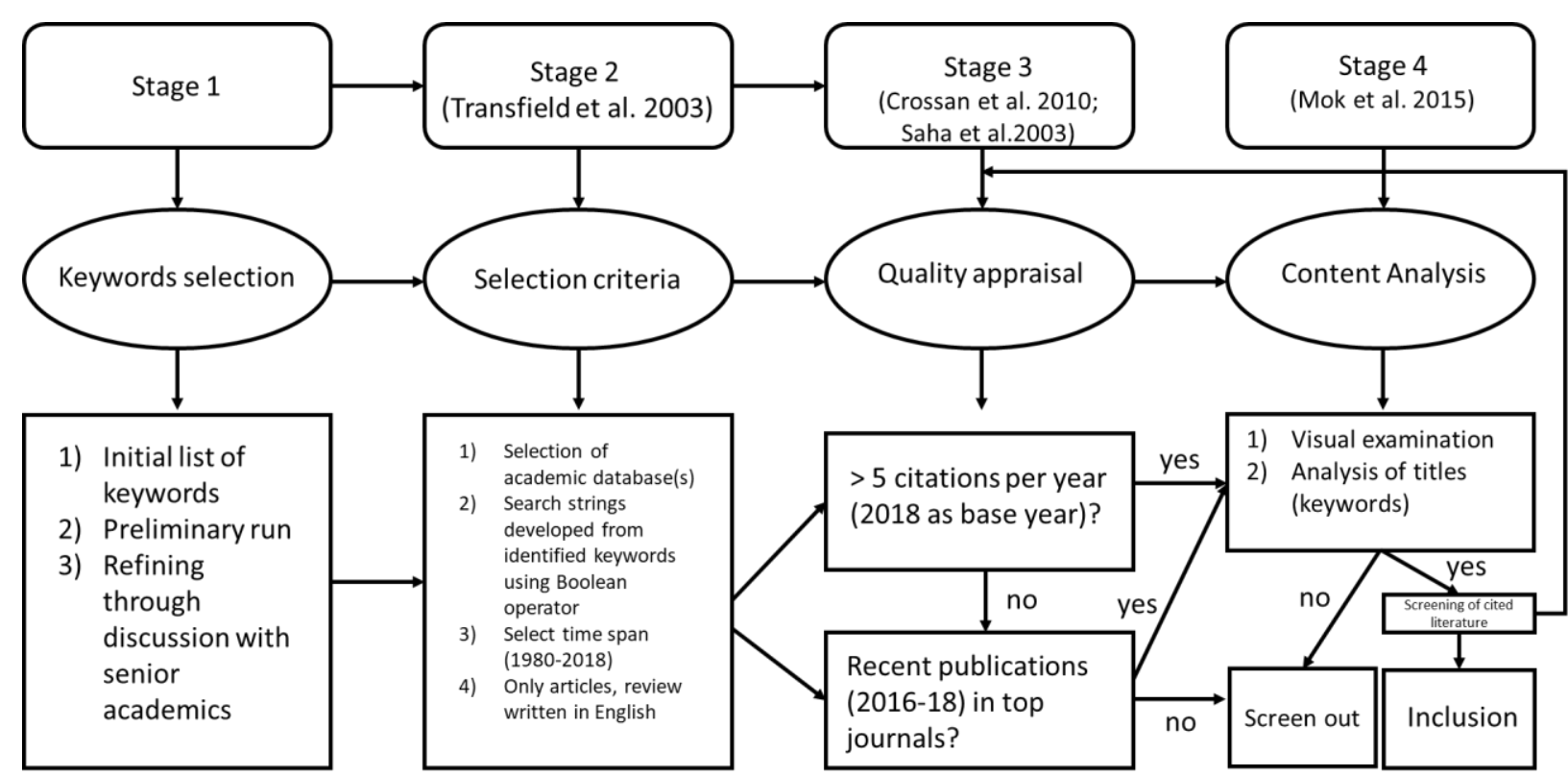

Note: adapted from (Di Maddaloni and Davis, 2017) and (Mok, Shen and Yang, 2015)

\section{Descriptive findings:}

(Tranfield, Denyer and Smart, 2003) suggest that findings should be articulated first by providing a "descriptive analysis" of the field using a set of categories with the use of the extraction forms. 
Accordingly, here we focus upon some descriptive metrics on the base of the 46 studies we identified.

First, the majority of articles we considered were published in the period from 2000 onwards (Figure 3 ) which reflect the current and growing interest on KT related topics. Articles were published in a total of 22 academic journals. However, research on knowledge and technology transfer mechanisms was predominantly published by two major academic journals: Research Policy (28\%) and The Journal of Technology Transfer (20\%). Despite the multidisciplinary of our research subject, studies were strongly focused on business, management and economics. The distribution of articles by geographic area (corresponding authors' reprint address) show that most works come from Europe (54\%) compared to North America (39\%). The USA and UK are the countries with the highest number of publications ( $35 \%$ and $22 \%$ respectively), followed by Italy, Denmark and Netherlands. The reported Anglo-Saxon hegemony ( 26 out of 46 papers published in USA or UK) can be explained by the success rates of technology transfer and the effect of 1980 Bayh-Dole act in the US and the strong productivity of the research system encouraged by the allocation of government funding in the UK (Decter, Bennett and Leseure, 2007). According to our inclusion criteria, publications were cited, on average, 20 times per year, 266 in total (Figure 2). In Appendix B we present an overview of the articles included in the review.

Figure 3: Synthesis of Articles, publications per year

\begin{tabular}{lc}
\hline \multicolumn{1}{c}{ Synthesis of Studies } & Number of Articles (no. 46) \\
\hline \hline $1994-9$ & 6 \\
$2000-4$ & 11 \\
$2005-10$ & 13 \\
$2010-18$ & 16 \\
Tot & 46 \\
& \\
Research Policy & 13 \\
The Journal of Technology & \\
Transfer & 9 \\
Management Science & 3 \\
R\&D Management & 2 \\
Technovation & 2 \\
Others & 17 \\
& \\
Citations (mean Tot) & 266 \\
Citations per year & 20 \\
Articles & 38 \\
Reviews & 8 \\
& \\
USA & 16 \\
UK & 10 \\
Italy & 4 \\
Denmark & 2 \\
Netherlands &
\end{tabular}

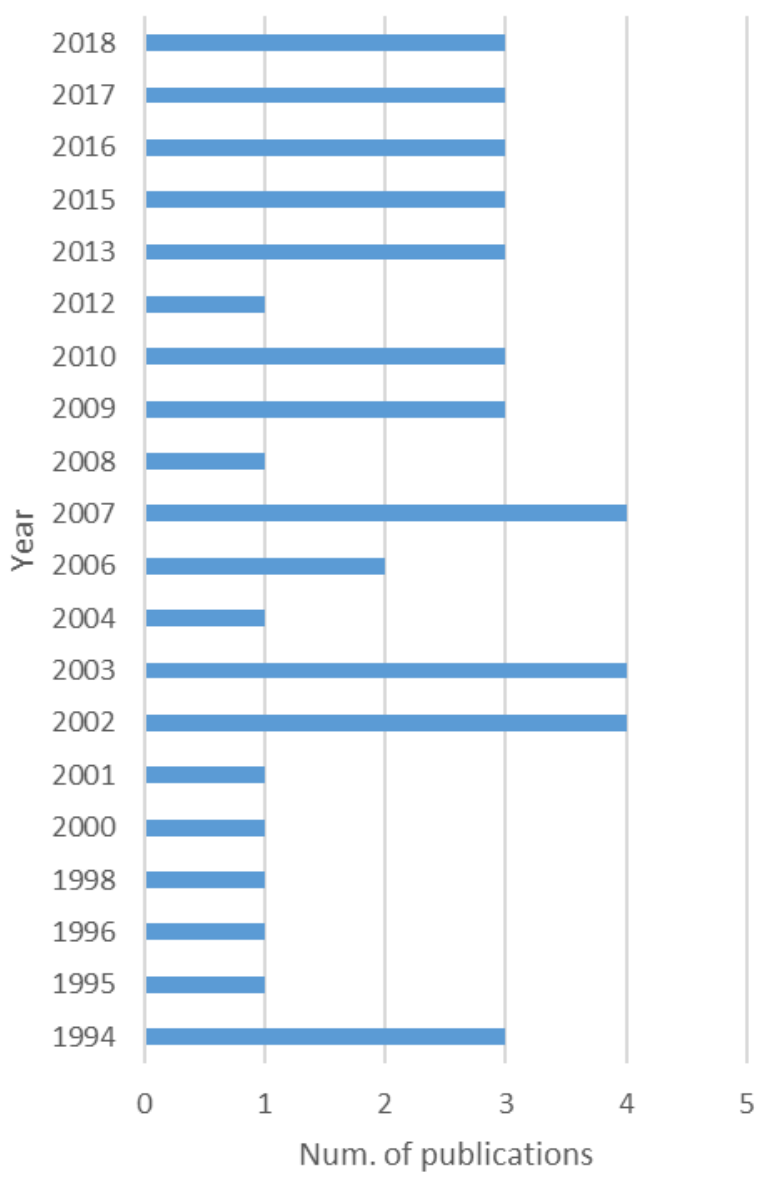




\section{Conceptual findings:}

Here we report a 'thematic analysis' in which we outline what is known and established from the core contributions as a result of our selection process (Tranfield, Denyer and Smart, 2003). We focus on the extent to which consensus is shared across different themes.

For this purpose, first we seek to explain what determines the adoption of different KT transfer. On the 46 publications included in the review, 30 fall in this category. Then, we present how scholars categorise the main mechanisms of knowledge transfer (12 publications). Four studies addressed more than one objective and thus they are employed in more than one section (Appendix B).

\subsection{Determinants of transfer activities:}

As a result of our literature review we found the features of knowledge, individuals, organizations and disciplines play a major role in determining the way in which university and industry establish their methods of interaction.

\section{Knowledge:}

The adoption of channels and/or processes as well as the success of a KT transfer are rooted around the characteristics of the object of the transfer. Since what is transferred is not only a particular technology, a patent or a physical artefact, but also the knowledge gained by the individual or by the company; characteristics of knowledge affect the way in which the transfer take place (Howells, 2002). The literature emphasizes the importance of knowledge characteristics such as level of codification, appropriability, and universality in shaping the knowledge development and transfer processes (Freitas and Verspagen, 2017). Another general knowledge characteristic often considered in the innovation studies literature and loosely associated with those dimensions is the degree of originality or novelty of the project objectives (Cassiman, Di Guardo and Valentini, 2010). (Zander and Kogut, 1995) further include the characteristic of 'teachability' as the degree to which knowledge can be taught; 'complexity' the degree to which knowledge embodies multiple kinds of competencies and 'system dependency' the degree to which knowledge requires many different experienced people for its application.

With regard to knowledge transfer, the basic argument reported in the literature is that different degrees of knowledge codification may require the use of different types of transfers. To this end, two dimensions of knowledge are commonly reported by published literatures on KT transfer: tacit and explicit. These concepts refers to the extent to which knowledge can be verbalized, written, drawn or otherwise articulated on the level of complexity of the knowledge continuum (Cummings and Teng, 2003; Liyanage et al., 2009).

Based on the seminal work by (Polanyi, 1962), tacit knowledge is not verbalised, intuitive and articulated. This type of knowledge is hard to communicate since it is rooted in action, involvement and commitment within a context and it resides in human brain (Cummings and Teng, 2003; Wong and Radcliffe, 2000). On the other hand, explicit knowledge can be articulated in formal language, hence codified and transferred in symbolic form (Alavi and Leidner, 2001).

These two states of knowledge are not dichotomous, but mutually dependent and reinforcing each other's (Alavi and Leidner, 2001). Research has shown that articulable or codified knowledge is more easily transferable. Contrarily, tacit knowledge requires the use of more complex means such as oral transmission or repeated observations embodied in researchers or workers (Cummings and Teng, 2003; Bonaccorsi and Piccaluga, 1994). 
Based on a survey conducted on four industrial sectors, (Bekkers and Freitas, 2008) suggest that differences in importance of various channels of knowledge transfer can be explained, to a large degree, by the basic characteristics of the knowledge in question: tacitness, systemicness and expected breakthroughs. Specifically, the more the knowledge can be written and published the more important 'Scientific output, informal contacts and students' as well as 'collaborative and contract research' and the less 'labour mobility' would be the forms of knowledge transfer between university and industry. Also, a codifiable body of knowledge could be transmitted through unambiguous information and impersonal communications (Bonaccorsi and Piccaluga, 1994).

Research has shown that when knowledge is embedded in individuals, whether tacit or explicit, such knowledge can be transferred by transferring individuals (Cummings and Teng, 2003). In this respect, (Bekkers and Freitas, 2008) found breakthrough knowledge seems to be mainly transferred through 'labour mobility'.

The importance of involving scientists in the process of knowledge transfer has been supported against the classic argument of most economic treatments for which discoveries have "fleeting value unless formal intellectual property rights mechanism prevent use of the information by unlicensed parties" (Zucker and Darby, 1996). Contrarily to this view, some authors argue that scientists' knowledge has high degrees of natural excludability (Jensen and Thursby, 2001). Moreover, vast majority of inventions licensed are so embryonic that there is a moral-hazard problem with regard to the inventor effort. Consequently, additional effort by the inventor is crucial for the success of commercial development.

Table 1: Key findings: knowledge

Scholars

- Transfer processes are shaped by the characteristics of knowledge such as: tacitness, codification, novelty, teachability, complexity, system dependency

Howells, 2002; Freitas and Verspagen, 2017; Cassiman Di Guardo and Valentini, 2010; Zander and Kogut, 1995

- Degrees of knowledge codification involve different transfer Cummings and Teng, 2003; mechanisms Liyanage et al., 2009; Wong and Radcliffe, 2000

- Codified knowledge is more easily transferable (collaborative, contract research and scientific outputs) whereas tacit knowledge requires more complex means (oral, labour mobility)

Cummings and Teng, 2003; Bonaccorsi and Piccaluga, 1994; Bekkers and Freitas, 2008

- Breakthrough knowledge is transferred with labour mobility

Bekkers and Freitas, 2008;

Zucker and Darby, 1996;

Jensen and Thursby, 2001

\section{Individuals:}

In the recent times there have been a growing focus on university-industry relationships from the perspective of the individuals involved in knowledge and technology transfer (Breschi and Catalini, 2010; Cunningham and O'Reilly, 2018; Cunningham et al., 2016). Scholars have become more aware that focusing solely on institutional characteristics may preclude new insights on the channels of knowledge transfer from university to industry (Owen-Smith and Powell, 2003; Breschi and Catalini, 2010; D’Este and Patel, 2007). 
A line of enquiry pioneered by Zucker and colleagues highlighted the value of labour mobility of 'star scientists' defined as those who had published 40 or more genetic sequence discoveries in GenBank. The involvement of star scientists in the founding of new firms or guiding existing ones are the essence of the 'virtuous circle' in which, in turn, stars drive greater success for firms which drive better publications for stars (Zucker and Darby, 2007). Articles by stars scientists who collaborate with or are employed by firms have also significantly higher rates of citation than other articles by the same or other stars (Zucker and Darby, 2006). This process was found to enhance the stature of universities and to draw other scientist into the circle with ancillary support organizations fostering the co-development of science and hence its commercial applications (Zucker and Darby, 2007).

(Baba, Shichijo and Sedita, 2009) found that being star scientists is not a sufficient condition. Contrarily, the involvement of 'Pasteur' scientists who perform 'use-inspired' basic research and 'Edison' scientists which are focused solely on applied research is determinant for R\&D productivity of firms in the field of advance materials.

Along a similar line, (Cockburn and Henderson, 1998) showed that firms strive to develop their capacity to tap into scientific development by recruiting and rewarding researchers based on their ranking in the hierarchy of public-sector science and their ability to engage with the academic community. Following this stream of research, the idea of technology transfer as 'movement of ideas in people' (Kenney and Patton, 2009) has shifted towards that of 'innovation' intended as the "commercial expression of new ideas by people" (Zucker and Darby, 2007). However, as pointed out by (Gittelman and Kogut, 2003), the relationship between research and innovation is more complex than a 'simple' human capital story would predict. To this end, authors demonstrated that highimpact innovations heavily build upon the scientific literature and are made by people who both invent and do research. Hence it is of a crucial importance for firms to maintain ties with the open science community via boundary-spanning 'gatekeepers' who facilitate access to socially embedded knowledge.

Recent researches on entrepreneurial ecosystems have taken the unit of individual analysis to provide new conceptual frameworks centred on the figure of the principal investigator (PI), (Cunningham, Menter and O'Kane, 2018). In the PI role, scientists take on management role in the governance, implementation and realization of large scale publicly funded research programs. Thus, Pls become the "linchpin of knowledge transformation" through their articulation of research programmes, the shaping of research avenues and the bridging of academia and industry (Mangematin, O'Reilly and Cunningham, 2014).

Another stream of inquiry has taken into consideration the role of individual 'academic entrepreneurs': faculty, technicians, postdoctoral fellows, or students who act as the primary entrepreneurial agent for the dissemination and commercialization of new knowledge generated in universities (Hayter, Lubynsky and Maroulis, 2017; Hayter et al., 2018; Faulkner and Senker, 1994).

Also graduate students were found of a great importance in university spin-off companies in which they formulate initial ideas and investigate the mechanics associated with firm establishment. Having a similar cognitive resources as researchers at universities graduates also increase the ability to absorb knowledge and embody the interface between universities and firms acting as gatekeeper (Lund Vinding, 2004; Hayter, Lubynsky and Maroulis, 2017).

Characteristics of researchers involved in producing and using this knowledge and the environment in which knowledge is produced and used are relevant to explain the variety in the importance of different channels of knowledge transfer from universities to firms. Researchers with a record of 
past interactions are more likely to be involved in a greater variety of interaction with the industry and be engaged across a wider set of channels. This, seems to play a greater role than the characteristics of their department or universities to which researchers are affiliated ( $D^{\prime}$ Este and Patel, 2007).

Finally, in the analysis of individual characteristics another aspect concerns the dualism between personal involvement and codification. In this respect, some literatures argued that informal mechanisms such as meetings and seminars can be effective in promoting socialization. However, these may involve a certain amount of 'knowledge atrophy' since, in absence of effective coding, "there is no guarantee that the knowledge will be passed accurately from one member to the other" (Alavi and Leidner, 2001). (Agrawal, 2006) refers to 'latent knowledge' as the knowledge who lack of adequate incentives to codification (such as that gained from failing experiments) which is, however, still valuable for commercialization if accessed by working directly with the inventor. This point led the attention of scholars to the learning problems that may involve recipients when filtering and interpreting and learning the knowledge they exchange. (Alavi and Leidner, 2001) reports that formal transfer mechanisms, may ensure greater distribution of knowledge at the expense of creativity. Opposite to that, personal channels, such as apprenticeships or personnel transfers, may be more effective for distributing highly context specific knowledge whereas impersonal channels, such as knowledge repositories, may be efficacious for knowledge that can be eagerly generalized to other contexts.

Table 2: Key findings: individuals

Scholars

- Transferring knowledge through star scientists drive

Zucker and Darby 2006,2007 greater success for firms and better publications for stars (virtuous circle)

- To be positively inclined towards inventions (pasteur scientists) in addition to a strong scientific reputation (stars) is a determinant for R\&D productivity

- Principal investigators, academic entrepreneurs and graduate students acting as entrepreneurial agents act as gatekeeper between firms and universities.

Baba, Shichijo and Sedita 2009;

Cockburn and Henderson 1998;

Kenney and Patton, 2009;

Gittelman and Kogut, 2003

Cunningham, Menter and O'Kane, 2018; Mangematin, O'Reilly and Cunningham, 2014; Hayter, Lubynsky and Maroulis, 2017; Hayter et al., 2018; Faulkner and Senker, 1994; Lund Vinding, 2004

D’Este and Patel, 2007

- Researchers with a record of past interactions with the industry are more likely to be involved in a greater variety of transfer activities

- Personal channels are more effective for transferring tacit knowledge however there still may be some Alavi and Leidner, 2001; Agrawal, 2006 learning problems and in absence of appropriate coding incentives.

\section{Organizations:}

For many years, knowledge and technology transfer were shaped by personal relationships with no, or few dedicated structures. The attention devoted to the so-called 'institutionalization' of KT activity as the third mission of universities moves its steps from the introduction of the Bayh-Dole 
Act of 1980 which granted universities the right to licence inventions resulting from federally funded research in the US and similar initiative in European countries (Sampat, 2006; Mowery and Ziedonis, 2015). Following that, the management of KT from the perspective of the academia has moved to assessing and protecting intellectual property (IP) and making it available to the industry (Geuna and Muscio, 2009). These changes promoted the establishment of Knowledge Transfer Organizations (KTO), i.e technology transfer offices (TTO) at universities and increased awareness towards the commercialization of research results.

Many universities have set up internal TTOs that aim to facilitate the KT transfer by reducing transaction costs and the hassles from patenting. Alternatively, 'external' organizational model consists of independent companies either fully owned or participated by the university together with other universities or companies while ' $\mathrm{mix}$ ' models are found as combination of internal office(s) and an external company-ies. (Brescia, Colombo and Landoni, 2016) claimed that the choice of the organizational structures depends on the country and university context. In particular, internal models are mainly adopted by highly cited universities which are less likely to separate their research from KT activities.

(Battaglia, Landoni and Rizzitelli, 2017) in analysing six consortia created by twenty Italian universities, recognized three different organizational models: 'network structure', 'strong' and 'light hubs'. Authors argue that network models are more suitable for universities that are trying to improve their competences rather than to learn new procedures. This structure does not involve direct co-working procedures but mainly sharing of procedures and codified knowledge. On the other hand, 'strong hubs' that encompass the creation of new unique offices, better allow the exchange of tacit knowledge. These are more suitable for those universities with a limited IP portfolio or that are generalist. Light hubs enable universities with small offices to achieve economies of scale without forcing them to renounce to their capabilities in some KT areas.

In addition to the external organizational models the structure conferred to the internal office has a direct impact on the amount of knowledge and technology transferred. On this point, (Bercovitz et al., 2001) argued that the best structure are semi-centralized in which semi-autonomous divisions, with different responsibilities, are managed by a central office with high decisional power.

Also, knowledge sharing can be influenced by the choice to configure collaborations between two or more offices. In this way, the transmission of tacit and explicit knowledge can be favoured through the building and maintenance of relationships to achieve strategic goals. Other reasons for organizational alliances rely in the possibility of reaching economies of scale and scope represented by cost advantages or the shared use of a physical asset (Battaglia, Landoni and Rizzitelli, 2017).

Table 3: Key findings: Organizations

Scholars

- Internal models are mainly adopted by highly cited Brescia, Colombo and universities which are less likely to separate their research from KT activities.

- Internal alliances are relevant to amount of transferred tacit and explicit knowledge and for reaching economies of scale or shared use of assets

Landoni, 2016

Bercovitz et al., 2001;

Battaglia, Landoni and Rizzitelli, 2017

- External network models are more suitable for sharing codified knowledge at universities that are trying to Battaglia, Landoni and Rizzitelli, 2017 improve their competences rather than to learn new procedures. Strong hubs allow the exchange of tacit knowledge and are more suitable for universities with a 
limited IP portfolio.

\section{Disciplines:}

Prior research indicate that scientific discipline is likely to play a role in different activities of technology and knowledge transfer. As argued by (Abreu and Grinevich, 2013), academics in the biological sciences, engineering and physics are more likely, relative to those in health sciences, to engage in all types of transfer activities, especially in more formal ones such as licensing and spinouts. Moreover, due to the discrete nature of inventions and long product-development horizon, spinouts are considered appropriate mechanism in life science (Owen-Smith and Powell, 2003).

In contrast, academics in the social sciences are more likely to be involved in less formal, informal and non-commercial activities. As such, research in humanities is often disseminated through public lectures and books that are considered as entrepreneurial activities in those fields (Abreu and Grinevich, 2013). Based on analysing academics' survey responses at four European universities, (Kalar and Antoncic, 2015) found that more academics in the natural sciences perceive their university department as being highly entrepreneurially oriented than their counterparts in the social sciences. Also, this may have a significant effect on academics engaging in entrepreneurial activities (patenting, licensing, business interactions, contract research) but a negligible effect on whether an academic would engage in more traditional activities (e.g. conferences, publishing, basic research).

Among the sectors categorized by the terms of 'science-based', the contribution of basic science is known to be very high in pharmaceuticals and chemicals. Biotechnology or related fields in the pharmaceutical sector are the only few industries where new ideas developed originally within university labs are quickly captured by industry (Cohen, Nelson and Walsh, 2002; Laursen and Salter, 2004). Here, the commercialization of science can be regarded as a form of one-way knowledge transfer from university scientists to corporate researchers in those industries. This seems due to the more knowledge-led character of innovation in pharmaceuticals and demanding heavily investment that make innovation more 'linear' in nature than in the other sectors (Faulkner and Senker, 1994). However, also here researchers rely heavily on published literature as a channel to obtain scientific or technological inputs from public sector research. On a similar line (Fritsch and Krabel, 2012) found considerable differences across fields of research in the attitude of scientists towards starting their own company or working in a private sector firm. The appeal to work in the private sector is particularly high in life sciences and low among researchers in humanities.

Finally, (Bekkers and Freitas, 2008) highlight that the sectoral activities of firms do not significantly explain differences in importance of a wide variety of channels for the transfer of knowledge between university and industry. Instead, it is the disciplinary origin and the characteristics of the underlying knowledge as well as the characteristics of researchers and the environment in which knowledge is produced that play the major role to explain the importance of different channels of knowledge transfer from universities to firms. 
- Biological sciences, engineering and physics engage in all types of transfer activities, especially in more formal such as licensing and spinouts. Social sciences are more likely to be involved in less formal, informal and non-commercial activities.

- In biotechnology or related fields in the pharmaceutical sector, the contribution of basic science and the use of publications is very high. Spinouts and academic entrepreneurs are frequent mechanisms too due to high investments needed.

- The sectorial activities of firms do not influence the Abreu and Grinevich, 2013; importance of channels but rather the disciplinary origin of the knowledge.

\subsection{Types of transfer activities:}

Previous studies present a number of ways in which the transfer of knowledge between the academia and the industry can be established. We employed four main dimensions for their categorisation: their degree of formalization, the relational involvement of actors, the direction and time of the relation. These are summarised in Table 5 and discussed in the following sections.

Table 5: classification of transfer activities 


\begin{tabular}{|c|c|c|c|c|}
\hline Author & Dimension(s) & Variable(s) & Classification & Terminology \\
\hline $\begin{array}{l}\text { (Grimpe and } \\
\text { Hussinger, 2008) }\end{array}$ & Formalization & Contractual relationship & $\begin{array}{l}\text { Formal(collaborative research, contract research, technology } \\
\text { consulting, licensing and acquisition of technologies developed at } \\
\text { universities)/ informal }\end{array}$ & Collaboration modes \\
\hline $\begin{array}{l}\text { (Bercovitz and } \\
\text { Feldman, 2006) }\end{array}$ & Formalization & Formal/Informal & $\begin{array}{l}\text { Sponsored research/Licenses/Hiring of students/Spin-off } \\
\text { firms/Serendipity }\end{array}$ & Mechanisms for transfer of research \\
\hline $\begin{array}{l}\text { (Schartinger, Rammer } \\
\text { and Fröhlich, 2006) }\end{array}$ & $\begin{array}{l}\text { Formalization/ } \\
\text { Relation }\end{array}$ & $\begin{array}{l}\text { Degree of formalization, transfer of } \\
\text { tacit knowledge, personal } \\
\text { interaction }\end{array}$ & Joint research/ contract research/ mobility/ training & Knowledge interactions \\
\hline $\begin{array}{l}\text { (Abreu and Grinevich, } \\
\text { 2013) }\end{array}$ & $\begin{array}{l}\text { Formalization/ } \\
\text { Relation }\end{array}$ & $\begin{array}{l}\text { Extent to which intellectual } \\
\text { property (IP) protection apply }\end{array}$ & Formal commercial/informal commercial/ non commercial & Entrepreneurial activities \\
\hline $\begin{array}{l}\text { (Nilsson, Rickne and } \\
\text { Bengtsson, 2010) }\end{array}$ & $\begin{array}{l}\text { Formalization/ } \\
\text { Relation }\end{array}$ & $\begin{array}{l}\text { Knowledge diffusion, transfer of } \\
\text { intellectual property, firm creation }\end{array}$ & $\begin{array}{l}\text { Publications/ patents/ licenses/ academic spin-offs/sponsored } \\
\text { research/Informal and pre-formal discussions/Shared personnel/ } \\
\text { Labour movement }\end{array}$ & Mechanisms for transfer of research \\
\hline $\begin{array}{l}\text { (D'Este and Patel, } \\
\text { 2007) }\end{array}$ & $\begin{array}{l}\text { Formalization/ } \\
\text { Time }\end{array}$ & $\begin{array}{l}\text { Resource deployment, length, } \\
\text { formalisation of agreements }\end{array}$ & $\begin{array}{l}\text { Meeting and conferences/consultancy and contract research/creation } \\
\text { of physical facilities/training/joint research }\end{array}$ & U-I interactions \\
\hline $\begin{array}{l}\text { (Perkmann and Walsh, } \\
\text { 2007) }\end{array}$ & Relation & $\begin{array}{l}\text { Extent of relational involvement, } \\
\text { degree of finalization }\end{array}$ & Relationship/mobility/transfer/research partnership/research services & Links, industry-funded research \\
\hline $\begin{array}{l}\text { (Bonaccorsi and } \\
\text { Piccaluga, 1994; } \\
\text { Ankrah and Omar, } \\
\text { 2015) }\end{array}$ & Relation/time & $\begin{array}{l}\text { Organisational resource } \\
\text { involvement from the university; } \\
\text { length of the agreement; degree of } \\
\text { formalisation. }\end{array}$ & $\begin{array}{l}\text { Personal informal relationship/personal formal relationship/third } \\
\text { parties/formal targeted agreements/formal non Targeted/ focused } \\
\text { structures }\end{array}$ & U-I relationships \\
\hline (Chen, 1994) & Time & $\begin{array}{l}\text { Duration of relationship, expected } \\
\text { technology flow to firms }\end{array}$ & Phase I/ phase II/ phase III/ low/high & U-I technology transfer mechanisms \\
\hline $\begin{array}{l}\text { (Dutrénit, De Fuentes } \\
\text { and Torres, 2010) }\end{array}$ & Direction & $\begin{array}{l}\text { Motivations to engage in linkages, } \\
\text { the direction of knowledge }\end{array}$ & Traditional/service/commercial/bi-directional & Channels of interaction \\
\hline $\begin{array}{l}\text { (Battistella, De Toni } \\
\text { and Pillon, 2016) }\end{array}$ & Direction & $\begin{array}{l}\text { Dissemination of the results of } \\
\text { research, interactive development, } \\
\text { creation of new and appropriate } \\
\text { organizational structures, service } \\
\text { activities. }\end{array}$ & Unidirectional/bidirectional & Transfer mechanisms \\
\hline
\end{tabular}


Formalization:

Many authors claim the difference between formal and informal channels is not clear-cut since these concepts have not been always defined in a mutually exclusive way. (Link, Siegel and Bozeman, 2007) distinguish between informal technology transfers as a mechanism facilitating the flow of technology knowledge through technical assistance, consulting or collaborative research in which property rights play a secondary role and obligations are normative. On the other hand, formal technology transfers are focused on allocation of property rights and legal obligations. (D'Este and Patel, 2007) propose a distinction between informal interactions, such as meetings and conferences that do not involve formal or signed agreement and consultancy and contract research which represent targeted, formal agreements including the definition of specific objectives within the contract. (Schartinger, Rammer and Fröhlich, 2006) identify four categories: joint research (including joint publishing), contract research (including consulting, financing of university research assistants by firms), mobility (staff movement between universities and firms, joint supervision of students) and training (co-operation in education, training of firm staff at universities, lecturing by industry staff). Based on these findings, formal links presuppose the establishment of formal contracts between the partners, with both the commitment and the payment of fees previously established (Vedovello, 1997). In this respect, (Mowery and Ziedonis, 2015) identify 'non-market' or 'knowledge spill-overs' the positive externalities from university scientific research as citations to university patents. Oppositely, 'market-mediated' are the various types of employment relationships between academia and industry represented by licensing agreements. The dualism between formal and informal transactions is adopted by (Bercovitz and Feldman, 2006) which categorise the formal activities in sponsored research support, agreements to license university intellectual property, the hiring of research students and new start-up firms and informal serendipity. (Nilsson, Rickne and Bengtsson, 2010) expanded these through empirical data from Swedish case studies by adding an outcome to each typology (Table 5).

However, when it comes to consider the dynamics between different actors (firms, scientists, universities) and the objectives they pursue, these activities become mutually reinforcing and the use of formal and informal transfer mostly coincide (Grimpe and Hussinger, 2008). Both formal and informal modes of technology transfer may go well together since informal contacts improve the quality of a formal relationship or formal contracts may be accompanied by an informal relation of mutual exchange on technology-related aspects (Grimpe and Hussinger, 2008; Link, Siegel and Bozeman, 2007; Siegel, Waldman and Link, 2003).

Relation:

(Schartinger, Rammer and Fröhlich, 2006) suggest that channels vary according to their suitability for transferring tacit knowledge and the degree to which they are based on personal face-to-face contacts. Based on a degree of 'relational involvement', (Perkmann and Walsh, 2007; Perkmann et al., 2013) define 'relationships' when there is a high level of involvement between individuals and teams working together on specific projects and producing common outputs (e.g. research partnerships and services). By contrast, the use of scientific publications and licensing of university IP require a low involvement between university researchers and industry whereas the transfer of human resources and academic entrepreneurship can be classified as having an intermediate relational involvement.

Furthermore, KT transfers can be distinguished as per their degree to which they aim at a specific purpose as opposed to gaining new knowledge for the sake of itself (e.g. blue-sky research), (Perkmann and Walsh, 2007). In this light, 'research partnerships' are of a low degree of finalization since they are designed to generate outputs of high academic relevance. On the other hand, 
'research services' are provided by researchers within the academy under the direction of industrial clients and tend to be less exploitable for publications.

\section{Direction:}

The direction of knowledge flow is employed by (Dutrénit, De Fuentes and Torres, 2010) to classify knowledge channels according to the motivations for public research organisations and firms to engage in unilateral or bi-directional linkages. (Baba, Shichijo and Sedita, 2009) attribute a 'university-to-industry' direction to the industrial settings where analytical knowledge is fundamental for innovation, i.e. biotechnology. Contrarily, 'industry-to-university' knowledge flow are the prevalent modality in which synthetic knowledge, concrete know-how and skills are required for an interactive learning mechanism between clients and suppliers. Based on that, unidirectional channels from universities to firm are: traditional channels such as teaching and researching or commercial channels provided in exchange for money or motivated by an attempt to commercialize scientific outputs. Bi-directional channels are instead motivated by long-term targets of knowledge creation by universities and innovation by firms. (Battistella, De Toni and Pillon, 2016) also emphasizes how technology transfer is a bilateral process of feedbacks involving a sender, a recipient and, eventually, a broker who assumes the role of facilitation between parties.

Time:

The existence of temporal continuity among formal and informal channels is also acknowledged since informal linkages are often both precursor and successor of formal linkages (Perkmann and Walsh, 2007; Faulkner and Senker, 1994). (Bercovitz and Feldman, 2006) refer to the 'serendipity' as informal activity which can be used to initiate a relationship but then develop into another form of formal transaction.Time duration is also adopted by (Chen, 1994) along with the expected technology flow to firms. Another factor adopted by researches to classify the transfer of KT is the duration of the agreement. (Chen, 1994) defines short mechanisms (phase I) those with little thought of technology transfer and lower direct benefit to firms. These generally take the form of unrestricted research grants, donations, fellowships and scholarships and reflect philanthropic motivations. Other short-term modes are university sponsored training programs, symposia and technical publications which serve to foster familiarity between academia and business. More intricate relationships such as liaison programs, personnel exchanges, sponsored research and faculty consulting generally have a medium-term duration of approximately one to three years (phase II). These may also involve the firm's establishment of a direct money-for-knowledge relationship with academic researchers in a mutual field of interest. Finally, the establishment of technology parks, industrial incubators and similar arrangements can span many years (phase III) and involve the location of company facilities in the physical proximity of the university.

The length of the agreement has also been employed by (Bonaccorsi and Piccaluga, 1994) to analyse university-industry inter-organizational relations. The proposed taxonomy consisted of six main categories involving increasing level of university's resource involvement, length and formalization of the agreement. Authors distinguish between a) 'personal informal relationships' between an individual inside the university and the firm without formal agreements involving the faculty; $b$ ) 'personal formal relationships' in which these interactions take place through a formal agreement; $c$ ) 'third parties' in which these are comprised relations that involve intermediary associations; d) 'formal targeted agreements' when specific objectives are defined since the beginning of the collaboration; e) 'formal non-targeted agreements' comprising long-term and strategic objectives and, finally f) 'focused structures' when initiatives are carried out within ad-hoc created permanent structures (Bonaccorsi and Piccaluga, 1994; Ankrah and Omar, 2015). 


\section{Discussion:}

\subsection{A new taxonomy:}

The literature review unfolded that relatively few attention has been paid to the dynamic relationship between types of knowledge transfer. Some authors claimed the existence of a 'temporal continuity' among channels, others demonstrated that researchers that showed previous experience were more likely to be involved in transferring knowledge. A number of works also relied on dynamic models of innovation encompassing a variety of interactions between academy and commercial sector. Despite of that, almost no evidence deals with the relationship between types of transfer activities. One partial exception is the work by (Azagra-Caro et al., 2017) which studies the localization of the economic impact spurring from the interaction between formal and informal channels. This study highlights the local economic impact is the result of a complex sequence of interactions. More importantly, the dynamic relation between channels demonstrated that knowledge generated during formal transfer activities could be transferred via informal channels.

These considerations make the avenue to a new taxonomy. Yet, the variety of frameworks encompassed in our review evidenced the need for a novel approach aimed at highlighting the complementarity and the dynamics between transfer activities. Based on the findings from other scholars, we have found the centrality of knowledge embedded in individuals, i.e researchers, determining the choice of transfer mechanisms. However, these elements are often seen in casual processes which result in theoretical categorizations that may affect the oneness of the overall phenomenon. For example, some authors argued that codified knowledge can be transferred through informal channels while tacit knowledge is embedded in individuals hence can be transferred through labour mobility. This, in our opinion, leads the representation of KT transfer as made of multiple but separated avenues in which the content knowledge move across organizational settings at different transfer rates. Doing so, the risk is of taking the perspective of the activity which is more capable of establishing a linear relation between source and recipient. This is reflected by the broad use of patents citations as a metric to assess the whole transfer phenomenon. In contrast, we argue the transfer of new knowledge would be more effectively embodied by a transfer process shared by the different means of the knowledge flow. These, from our perspective can be categorized as:

- Channels are media through which encoded knowledge is transferred (unidirectional) in absence of ad-hoc agreements and with low relational and organisational involvement whose access can be market-mediated not involving long term transactions.

- Processes are social configurations in which coded and encoded knowledge is shared (multidirectional) with an increasing level of relational involvement. The output may take the form of a contract involving multiple external parties or the constitution of ad-hoc structures; with economic aspects, duration and penalties stated.

This classification rests on the distinction between media and social configurations. Media are intended here as the means or tools to transmit knowledge and information. Under this definition we include transfer activities such as publications, citations, lectures, access to databases, endowments, gifts, grants, commercialization of IP - patent, licensing (figure 4). These channels are conceived as unidirectional avenues bridging the source of knowledge and the recipient. Here, the cognitive content is meant to be transmittable, codifiable and protectable against the risk of appropriation. For this reason, channels are represented in our model as linear, unidirectional relations connecting universities and industry allowing the transfer of third elements external to both the source and the recipients. 
On the other hand, social configurations are systems made of interdependent actions which in turn enable the creation and the transmission of knowledge. Processes are seen as a virtuous circles in which the source's personal involvement is a key aspect for transferring notions to the environment who, in turn, adapt, learn and absorb the knowledge content. Such configurations are conceived as learning processes made of multiple feedback loops which require "hands-on experience" (Zucker and Darby, 2006). These enable successful communications between who holds the knowledge content and the recipients.

In our conceptual model (Figure 4), processes are circular spaces of interaction made of different radius that measure the degree of relational involvement. Through these lens, the characteristics of knowledge fuel and shape the adoption of multiple means and configurations that are not exclusive but rather complementary each other's.

Accordingly to our review, we expect the adoption of channels to be driven by the characteristics of knowledge and the disciplinary origin rather than the industrial activities of firms. Therefore, our conceptual model can be seen as a framework in which different disciplines apply consistently to the knowledge content. To this extent, our review found that applied or user-inspired research lends itself more readily to informal arrangements due to the straightforward benefits to external partners that not impose the use of IP protection (Abreu and Grinevich, 2013). This was true for scholars in arts, social sciences and the humanities due also to the nature of the potential commercial partners, less likely to have financial resources to engage in formal IP activities. However, informal information exchange and consulting were found to be widely important across industries (Bekkers and Freitas, 2008). On the other hand, our review also confirm the predominant role played by life sciences in commercialization activities as well as the reliance on basic, academic knowledge reflects into a higher importance of patents, spin-offs and collaborative research.

Therefore, on one side, we conceived processes as multidimensional spaces in which the thickness of the relational circles reflect the degree of informal involvement. On the other side, channels are meant to play as unidirectional conducts in which knowledge move at different speeds accordingly to formalization. In this framework, due to the relevance of personal involvement in KT activities, disciplines are meant to have multiple transportation modes that ultimately convey into the same organizational environment of destination.

Figure 4: Channels and processes of KT transfer, conceptual model

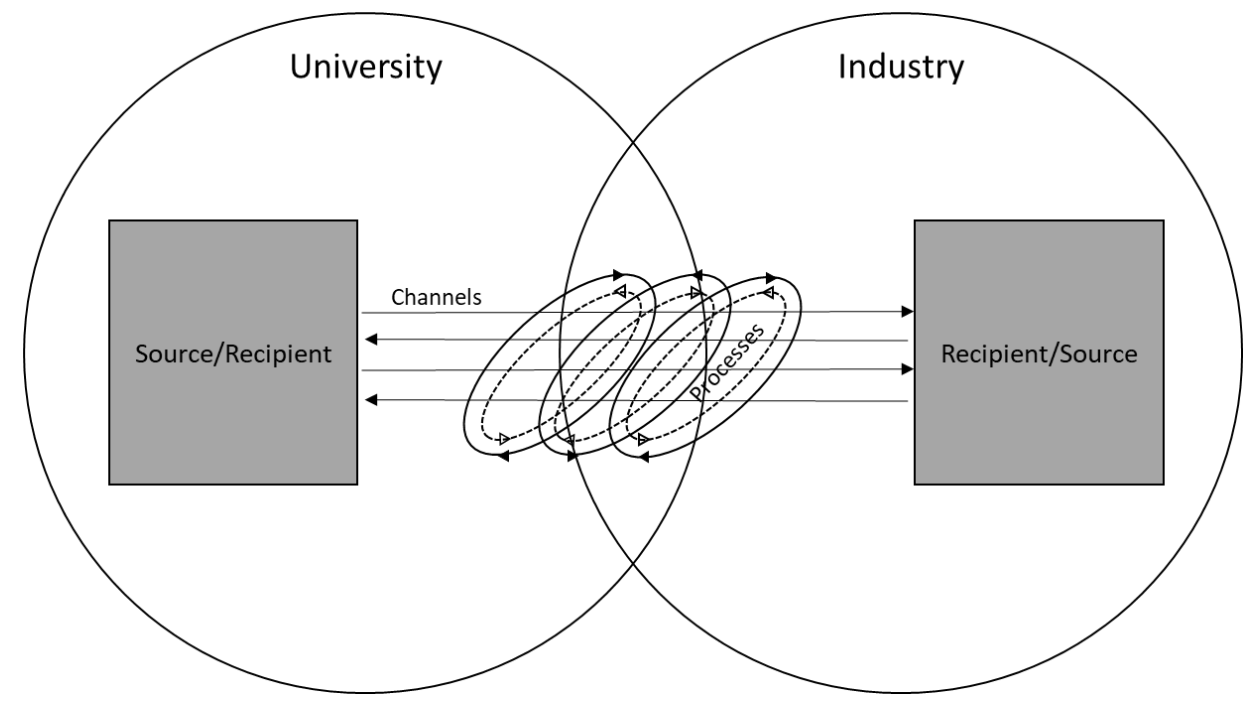




\subsection{Future Research:}

In this article, we sought to provide a twofold contribution from the review of the extant literature. We proposed an analysis of the overarching emphasis in prior research regarding the phenomenon of knowledge and technology transfer linking the academia to industry. Pertinent issues were highlighted and presented through a content analysis of the published evidences. Additional research efforts are encouraged to exploit some of the findings under the lens of the proposed new conceptualization. First, future analyses should be tailored on the revealed multidimensionality of the KT processes. To date, KT mechanisms have largely been assumed as uni- rather than multidirectional processes. Based on the contribution of our study, future research should explore this phenomenon to test what facets of U-I collaborations enable the contemporary adoption of multiple channels and processes of knowledge transfer. Secondly, their interrelation should be further investigated and, as suggested by Vick et al. 2017, the cumulative role of internal and external intermediaries in the process of $\mathrm{KT}$ should be accounted for future examinations. These shall require a longitudinal approach to highlight the role of multiple factors both in fostering and impeding the view of KT transfer as a dynamic process over time. With the advent digital revolution, Big Data represents an interesting case for the application of such multidimensional knowledge transfer. Big data knowledge make enterprises to have difficulties defining the source of the knowledge transfer as well as to manage the timing of transfer activities and the potential intellectual property risk. Given the characteristics of Big Data: volume, diversity, speed and veracity (Koman and Kundrikova, 2016); the multidimensional feature of our model could be taken as starting point for future investigations on big data transfer between public institutions, which usually are in possess of large amount of information (e.g. hospital administrative data) and the private sector. Thirdly, further research is required on the economic aspects related to the adoption of transfer mechanisms. We evidenced most economic considerations on KT transfer stem from the analysis of patents commercialization. Instead few contributions were found which analysed other economic drivers from the perspective of the actors involved in the financing of such activities. An exemption is the work by (Agrawal, 2006) which found that when firms engage the inventor favourably influence the likelihood and degree of commercialization success. This point may be further explored to highlight the role of policy makers into shaping the adoption of transfer mechanisms and therefore extend this analysis to the interaction between public and private entities. Under this light we expect a number of transfer activities to happen between universities or public entities as well as between companies. Therefore, future contributions should be tailored on the collaborations between universities as well as companies in order to analyse the economic aspects driving the adoption of transfer mechanisms. Doing so, these contributions shall inform policy decisions on the allocation of funding for innovation. Future empirical investigations should be also made with regard to the industries which are highly specialized such as biomedical and pharmaceutical and their role with national innovation systems.

Based on the previous discussion we conclude by reporting some limitations we encountered in the conduction of our review and selection of the relevant evidences. Noted limitations are that this paper is conceptual in nature and although bias in the literature selection was minimized by employing a systematic framework the authors acknowledge the drawbacks associated with the systematic literature review methodology (Mostafa, Chileshe and Abdelhamid, 2016; Denyer and Tranfield, 2009). The main drawbacks include the literature sampling criteria and methods for inclusion and exclusion related to content analysis which, although executed with rigor, remains a subjective interpretation of the authors. 


\section{Conclusions:}

This study concludes the knowledge content, embedded in individuals or processes within organizations, is the main component which drives the adoption of knowledge transfer mechanisms. Knowledge transfer between universities and industry take place through a variety of ways which are re-defined here into channels and processes.

In this study we found as previous scholars refer to four main levers of categorizations of KT transfer. First, the level of formalization, intended as the extent to codify the knowledge content into transferable and marketable media. Second, the relational involvement of the actors involved in the transfer which also imply a more tacit knowledge to be transferred by involving individuals. Multiple directions of KT and temporal interactions between mechanisms were also ascertained.

The adoption of different channels and processes are also shaped by the organizational features of the sources and recipients and a fundamental role was played by fields of science which reflected differences in the demand for knowledge and technology for innovation.

This research contributed the current knowledge both by encompassing the variety of knowledge interactions found in the literature and reorganizing them into a new taxonomy. This was proposed with the intention to clarifying the use of different terminologies and to help converging on a shared view. This analysis confirms that knowledge transfer between university and industry is made of complex patterns of interaction. However, there is a need to take this aspect into account for future research. Therefore, we proposed a conceptualization of the different determinants and features evidenced in the literature in a new taxonomy which is aimed at modelling the revealed complexity and multidimensionality.

Based on that, we encourage empirical analyses to provide additional insights into the dynamics of interaction between channels and processes and help assessing the outcomes on policies of this model in short and long term scales.

\section{Bibliography:}

Abreu, M. and Grinevich, V. (2013) 'The nature of academic entrepreneurship in the UK: Widening the focus on entrepreneurial activities', Research Policy, 42 (2), pp. 408-422.

Agrawal, A. (2006) 'Engaging the inventor: Exploring licensing strategies for university inventions and the role of latent knowledge', Strategic Management Journal, 27 (1), pp. 63-79.

Alavi, M. and Leidner, D. E. (2001) 'Knowledge management and knowledge management systems: Conceptual foundations and research issues', MIS Quarterly, pp. 107-136.

Ankrah, S. and Omar, A. (2015) 'Universities-industry collaboration: A systematic review', Scandinavian Journal of Management, 31 (3), pp. 387-408.

Azagra-Caro, J. M., Barberá-Tomás, D., Edwards-Schachter, M. and Tur, E. M. (2017) 'Dynamic interactions between university-industry knowledge transfer channels: A case study of the most highly cited academic patent', Research Policy, 46 (2), pp. 463-474.

Baba, Y., Shichijo, N. and Sedita, S. R. (2009) 'How do collaborations with universities affect firms' innovative performance? The role of "Pasteur scientists" in the advanced materials field', Research Policy, 38 (5), pp. 756-764.

Battaglia, D., Landoni, P. and Rizzitelli, F. (2017) 'Organizational structures for external growth of university technology transfer offices: an explorative analysis', Technological Forecasting and Social Change, 123 pp. 45-56. 
Battistella, C., De Toni, A. F. and Pillon, R. (2016) 'Inter-organisational technology/knowledge transfer: A framework from critical literature review', The Journal of Technology Transfer, 41 (5), pp. 1195-1234.

Bekkers, R. and Freitas, I. M. B. (2008) 'Analysing knowledge transfer channels between universities and industry: To what degree do sectors also matter?', Research Policy, 37 (10), pp. 1837-1853.

Bercovitz, J. and Feldman, M. (2006) 'Entpreprenerial universities and technology transfer: A conceptual framework for understanding knowledge-based economic development', The Journal of Technology Transfer, 31 (1), pp. 175-188.

Bercovitz, J., Feldman, M., Feller, I. and Burton, R. (2001) 'Organizational structure as a determinant of academic patent and licensing behavior: An exploratory study of Duke, Johns Hopkins, and Pennsylvania State Universities', The Journal of Technology Transfer, 26 (1-2), pp. 21-35.

Bonaccorsi, A. and Piccaluga, A. (1994) 'A theoretical framework for the evaluation of university-industry relationships', R\&D Management, 24 (3), pp. 229-247.

Bozeman, B. (2000) 'Technology transfer and public policy: a review of research and theory', Research Policy, 29 (4-5), pp. 627-655.

Breschi, S. and Catalini, C. (2010) 'Tracing the links between science and technology: An exploratory analysis of scientists' and inventors' networks', Research Policy, 39 (1), pp. 14-26.

Brescia, F., Colombo, G. and Landoni, P. (2016) 'Organizational structures of Knowledge Transfer Offices: an analysis of the world's top-ranked universities', The Journal of Technology Transfer, 41 (1), pp. 132-151.

Burrows, R. (2000) 'Methodologies for Socially Useful Systematic Reviews in Social Policy', End of Award Report, ESRC, .

Cassiman, B., Di Guardo, M. C. and Valentini, G. (2010) 'Organizing links with science: Cooperate or contract?: A project-level analysis', Research Policy, 39 (7), pp. 882-892.

Chang, Y., Yang, P. Y. and Chen, M. (2009) 'The determinants of academic research commercial performance: Towards an organizational ambidexterity perspective', Research Policy, 38 (6), pp. 936946.

Chen, E. Y. (1994) 'The evolution of university-industry technology transfer in Hong Kong', Technovation, 14 (7), pp. 449-459.

Cockburn, I. M. and Henderson, R. M. (1998) 'Absorptive capacity, coauthoring behavior, and the organization of research in drug discovery', The Journal of Industrial Economics, 46 (2), pp. 157-182.

Cohen, W. M., Nelson, R. R. and Walsh, J. P. (2002) 'Links and impacts: the influence of public research on industrial R\&D', Management Science, 48 (1), pp. 1-23.

Crossan, M. M. and Apaydin, M. (2010) 'A multi-dimensional framework of organizational innovation: A systematic review of the literature', Journal of Management Studies, 47 (6), pp. 11541191.

Cummings, J. L. and Teng, B. (2003) 'Transferring R\&D knowledge: the key factors affecting knowledge transfer success', Journal of Engineering and Technology Management, 20 (1-2), pp. 3968.

Cunningham, J. A., Mangematin, V., O'Kane, C. and O'Reilly, P. (2016) 'At the frontiers of scientific advancement: The factors that influence scientists to become or choose to become publicly funded principal investigators', The Journal of Technology Transfer, 41 (4), pp. 778-797. 
Cunningham, J. A., Menter, M. and O'Kane, C. (2018) 'Value creation in the quadruple helix: a micro level conceptual model of principal investigators as value creators', $R \& D$ Management, 48 (1), pp. 136-147.

Cunningham, J. A. and O'Reilly, P. (2018) 'Macro, meso and micro perspectives of technology transfer', The Journal of Technology Transfer, 43 (3), pp. 545-557.

D'Este, P. and Patel, P. (2007) 'University-industry linkages in the UK: What are the factors underlying the variety of interactions with industry?', Research Policy, 36 (9), pp. 1295-1313.

Decter, M., Bennett, D. and Leseure, M. (2007) 'University to business technology transfer-UK and USA comparisons', Technovation, 27 (3), pp. 145-155.

Denyer, D. and Tranfield, D. (2009) 'Producing a systematic review.', .

Di Maddaloni, F. and Davis, K. (2017) 'The influence of local community stakeholders in megaprojects: Rethinking their inclusiveness to improve project performance', International Journal of Project Management, 35 (8), pp. 1537-1556.

Dutrénit, G., De Fuentes, C. and Torres, A. (2010) 'Channels of interaction between public research organisations and industry and their benefits: evidence from Mexico', Science and Public Policy, 37 (7), pp. 513-526.

Etzkowitz, H. and Leydesdorff, L. (2000) 'The dynamics of innovation: from National Systems and "Mode 2" to a Triple Helix of university-industry-government relations', Research Policy, 29 (2), pp. 109-123.

Etzkowitz, H. and Leydesdorff, L. (1997) Introduction to Special Issue on Science Policy Dimensions of the Triple Helix of University-Industry-Government Relations, .

Faulkner, W. and Senker, J. (1994) 'Making sense of diversity: public-private sector research linkage in three technologies', Research Policy, 23 (6), pp. 673-695.

Freitas, I. M. B. and Verspagen, B. (2017) 'The motivations, institutions and organization of university-industry collaborations in the Netherlands', Journal of Evolutionary Economics, 27 (3), pp. 379-412.

Fritsch, M. and Krabel, S. (2012) 'Ready to leave the ivory tower?: Academic scientists' appeal to work in the private sector', The Journal of Technology Transfer, 37 (3), pp. 271-296.

Geuna, A. and Muscio, A. (2009) 'The governance of university knowledge transfer: A critical review of the literature', Minerva, 47 (1), pp. 93-114.

Gittelman, M. and Kogut, B. (2003) 'Does good science lead to valuable knowledge? Biotechnology firms and the evolutionary logic of citation patterns', Management Science, 49 (4), pp. 366-382.

Gopalakrishnan, S. and Santoro, M. D. (2004) 'Distinguishing between knowledge transfer and technology transfer activities: The role of key organizational factors', IEEE Transactions on Engineering Management, 51 (1), pp. 57-69.

Grimpe, C. and Hussinger, K. (2008) Formal and Informal Technology Transfer from Academia to Industry: Complementarity Effects and Innovation Performance, .

Hayter, C. S., Lubynsky, R. and Maroulis, S. (2017) 'Who is the academic entrepreneur? The role of graduate students in the development of university spinoffs', The Journal of Technology Transfer, 42 (6), pp. 1237-1254. 
Hayter, C. S., Nelson, A. J., Zayed, S. and O'Connor, A. C. (2018) 'Conceptualizing academic entrepreneurship ecosystems: a review, analysis and extension of the literature', The Journal of Technology Transfer, pp. 1-44.

Howells, J. R. (2002) 'Tacit knowledge, innovation and economic geography', Urban Studies, 39 (5-6), pp. 871-884.

Jensen, R. and Thursby, M. (2001) 'Proofs and prototypes for sale: The licensing of university inventions', American Economic Review, 91 (1), pp. 240-259.

Kalar, B. and Antoncic, B. (2015) 'The entrepreneurial university, academic activities and technology and knowledge transfer in four European countries', Technovation, 36 pp. 1-11.

Kenney, M. and Patton, D. (2009) 'Reconsidering the Bayh-Dole Act and the current university invention ownership model', Research Policy, 38 (9), pp. 1407-1422.

Koman, G. and Kundrikova, J. (2016) 'Application of big data technology in knowledge transfer process between business and academia', Procedia Economics and Finance, 39 pp. 605-611.

Laursen, K. and Salter, A. (2004) 'Searching high and low: what types of firms use universities as a source of innovation?', Research Policy, 33 (8), pp. 1201-1215.

Leydesdorff, L. and Etzkowitz, H. (1998) 'The triple helix as a model for innovation studies', Science and Public Policy, 25 (3), pp. 195-203.

Leydesdorff, L. and Etzkowitz, H. (1996) 'Emergence of a Triple Helix of university-industrygovernment relations', Science and Public Policy, 23 (5), pp. 279-286.

Link, A. N., Siegel, D. S. and Bozeman, B. (2007) 'An empirical analysis of the propensity of academics to engage in informal university technology transfer', Industrial and Corporate Change, 16 (4), pp. 641-655.

Liyanage, C., Elhag, T., Ballal, T. and Li, Q. (2009) 'Knowledge communication and translation-a knowledge transfer model', Journal of Knowledge Management, 13 (3), pp. 118-131.

Lund Vinding, A. (2004) 'Interaction between firms and knowledge institutions', in 'Interaction between firms and knowledge institutions', in Product Inovation, Interactive Learning and Economic Performance. Emerald Group Publishing Limited, pp. 257-283.

Mangematin, V., O'Reilly, P. and Cunningham, J. (2014) 'PIs as boundary spanners, science and market shapers', The Journal of Technology Transfer, 39 (1), pp. 1-10.

Mansfield, E. (1991) 'Academic research and industrial innovation', Research Policy, 20 (1), pp. 1-12.

Meyer-Krahmer, F. and Schmoch, U. (1998) 'Science-based technologies: university-industry interactions in four fields', Research Policy, 27 (8), pp. 835-851.

Moher, D., Liberati, A., Tetzlaff, J. and Altman, D. G. (2009) 'Preferred reporting items for systematic reviews and meta-analyses: the PRISMA statement', Annals of Internal Medicine, 151 (4), pp. 264269.

Mok, K. Y., Shen, G. Q. and Yang, J. (2015) 'Stakeholder management studies in mega construction projects: A review and future directions', International Journal of Project Management, 33 (2), pp. 446-457.

Mostafa, S., Chileshe, N. and Abdelhamid, T. (2016) 'Lean and agile integration within offsite construction using discrete event simulation: A systematic literature review', Construction Innovation, 16 (4), pp. 483-525. 

research', Research Policy, 44 (1), pp. 50-66.

Nilsson, A. S., Rickne, A. and Bengtsson, L. (2010) 'Transfer of academic research: uncovering the grey zone', The Journal of Technology Transfer, 35 (6), pp. 617-636.

Owen-Smith, J. and Powell, W. W. (2003) 'The expanding role of university patenting in the life sciences: assessing the importance of experience and connectivity', Research Policy, 32 (9), pp. 16951711.

Pavitt, K. (1991) 'What makes basic research economically useful?', Research Policy, 20 (2), pp. 109119.

Perkmann, M., Tartari, V., McKelvey, M., Autio, E., Broström, A., D’Este, P., Fini, R., Geuna, A., Grimaldi, R. and Hughes, A. (2013) 'Academic engagement and commercialisation: A review of the literature on university-industry relations', Research Policy, 42 (2), pp. 423-442.

Perkmann, M. and Walsh, K. (2007) 'University-industry relationships and open innovation: Towards a research agenda', International Journal of Management Reviews, 9 (4), pp. 259-280.

Polanyi, M. (1962) 'Tacit knowing: Its bearing on some problems of philosophy', Reviews of Modern Physics, 34 (4), pp. 601.

Poyago-Theotoky, J., Beath, J. and Siegel, D. S. (2002) 'Universities and fundamental research: reflections on the growth of university-industry partnerships', Oxford Review of Economic Policy, 18 (1), pp. 10-21.

Roessner, J. (2000) 'Technology transfer', Science and Technology Policy in the US.A Time of Change.Longman, London, .

Rosenberg, N. and Nelson, R. R. (1994) 'American universities and technical advance in industry', Research Policy, 23 (3), pp. 323-348.

Saha, S., Saint, S. and Christakis, D. A. (2003) 'Impact factor: a valid measure of journal quality?', Journal of the Medical Library Association : JMLA, 91 (1), pp. 42-46.

Salter, A. J. and Martin, B. R. (2001) 'The economic benefits of publicly funded basic research: a critical review', Research Policy, 30 (3), pp. 509-532.

Sampat, B. N. (2006) 'Patenting and US academic research in the 20th century: The world before and after Bayh-Dole', Research Policy, 35 (6), pp. 772-789.

Schartinger, D., Rammer, C. and Fröhlich, J.(2006) 'Knowledge interactions between universities and industry in Austria: sectoral patterns and determinants', in 'Knowledge interactions between universities and industry in Austria: sectoral patterns and determinants', in Innovation, Networks, and Knowledge Spillovers. Springer, pp. 135-166.

Siegel, D. S., Waldman, D. and Link, A. (2003) 'Assessing the impact of organizational practices on the relative productivity of university technology transfer offices: an exploratory study', Research Policy, 32 (1), pp. 27-48.

Tranfield, D., Denyer, D. and Smart, P. (2003) 'Towards a methodology for developing evidence-informed management knowledge by means of systematic review', British Journal of Management, 14 (3), pp. 207-222.

Vedovello, C. (1997) 'Science parks and university-industry interaction: geographical proximity between the agents as a driving force', Technovation, 17 (9), pp. 491-531. 
Vick, T. E. and Robertson, M. (2017) 'A systematic literature review of UK university-industry collaboration for knowledge transfer: A future research agenda', Science and Public Policy, .

Wong, W. and Radcliffe, D. F. (2000) 'The tacit nature of design knowledge', Technology Analysis \& Strategic Management, 12 (4), pp. 493-512.

Zander, U. and Kogut, B. (1995) 'Knowledge and the speed of the transfer and imitation of organizational capabilities: An empirical test', Organization Science, 6 (1), pp. 76-92.

426 Zucker, L. G. and Darby, M. R. (2007) 'Virtuous circles in science and commerce', Papers in Regional 427 Science, $86(3)$, pp. 445-470.

Zucker, L. G. and Darby, M. R. (2006) Movement of Star Scientists and Engineers and High-Tech Firm Entry, .

Zucker, L. G. and Darby, M. R. (1996) 'Star scientists and institutional transformation: patterns of invention and innovation in the formation of the biotechnology industry', Proceedings of the National Academy of Sciences of the United States of America, 93 (23), pp. 12709-12716. 
455

456

$4 !$

$4 !$ IXISMA PRISMA 2009 Flow Diagram

$4 !$

460

461

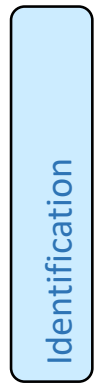

$$
\begin{gathered}
\text { Records identified through database } \\
\text { searching } \\
(n=2,288)
\end{gathered}
$$

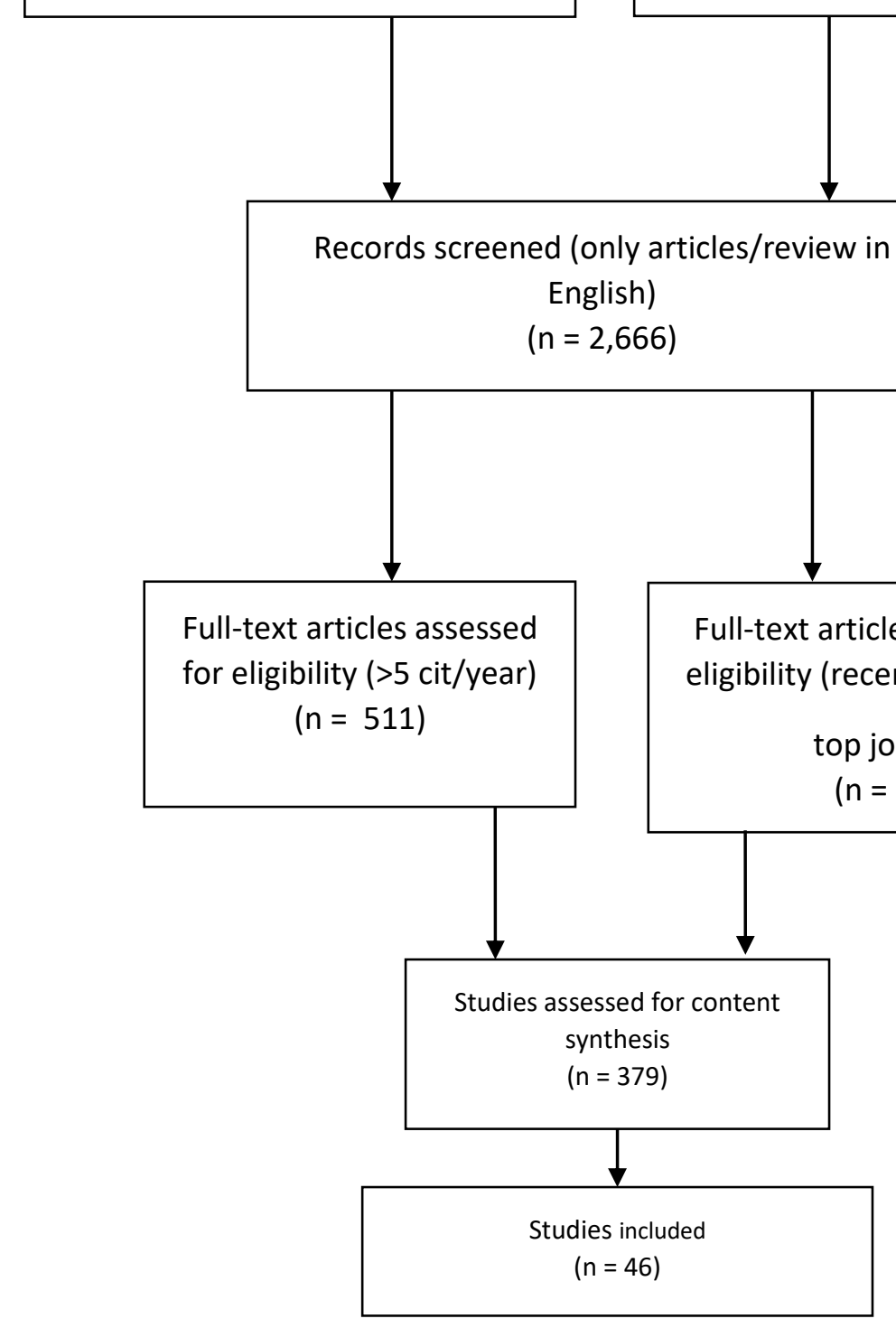

Additional records identified through other sources $(n=88)$

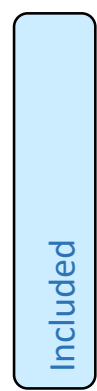




\section{Appendix B: Overview of the articles included in the review}

485 Keywords used for search (October 2018, Web of Science):

486

TS $=(($ research OR science OR intellectual OR discover* OR invent*) AND (((universit* OR academ*) AND (industry)) AND (interact* OR engag* OR relat* OR collab*)) AND ((knowledge OR technology) AND (transfer* OR link* OR channel* OR mechanism*)))

Top-Journals for quality appraisal:

492

Fields included:

- Economics, Econometrics and Statistics

- Finance

- Innovation

- International Business \& Area studied

- Management Development and Education

- Operations Research and Management Science Social Sciences

- Public Sector and Health Care

Rankings according to ABS definition (2018):

- $\quad 4^{*}$ Journals of Distinction. Within the business and management field, including economics, there are a small number of grade 4 journals that are recognised world-wide as exemplars of excellence. As the world leading journals in the field, they would be ranked among the highest in terms of impact factor. The initial paper selection and review process would be rigorous and demanding. Accepted papers would typically not only bring to bear large scale data and/or rigour in theory, but also be extremely finely crafted and provide major advances to their field.

- 4 All journals rated 4 , whether included in the Journal of Distinction category or not publish the most original and best-executed research. As top journals in their field, these journals typically have high submission and low acceptance rates. Papers are heavily refereed. These top journals generally have among the highest citation impact factors within their field.

- 3 rated journals publish original and well executed research papers and are highly regarded. These journals typically have good submission rates and are very selective in what they publish. Papers are heavily refereed. These highly regarded journals generally have good to excellent journal metrics relative to others in their field, although at present not all journals in this category carry a citation impact factor.

- 2 Journals in this category publish original research of an acceptable standard. For these well regarded journals in their field, papers are fully refereed according to accepted standards and conventions. Citation impact factors are somewhat more modest in certain cases. Many excellent practitioner oriented articles are published in 2-rated journals. 


\begin{tabular}{|c|c|c|}
\hline Journal Title & $\begin{array}{l}\text { Total no. } \\
\text { of articles }\end{array}$ & Articles included in the analysis \\
\hline RESEARCH POLICY & 13 & $\begin{array}{l}\text { (Abreu and Grinevich, 2013; Baba, Shichijo and } \\
\text { Sedita, 2009; Bekkers and Freitas, 2008; } \\
\text { Bercovitz et al., 2001; Breschi and Catalini, 2010; } \\
\text { Cassiman, Di Guardo and Valentini, 2010; D’Este } \\
\text { and Patel, 2007; Faulkner and Senker, 1994; } \\
\text { Kenney and Patton, 2009; Laursen and Salter, } \\
\text { 2004; Mowery and Ziedonis, 2015; Owen-Smith } \\
\text { and Powell, 2003; Perkmann and Walsh, 2007; } \\
\text { Sampat, 2006; Schartinger, Rammer and } \\
\text { Fröhlich, 2006; Siegel, Waldman and Link, 2003) }\end{array}$ \\
\hline JOURNAL OF TECHNOLOGY TRANSFER & 9 & $\begin{array}{l}\text { (Battistella, De Toni and Pillon, 2016; Brescia, } \\
\text { Colombo and Landoni, 2016; Cunningham and } \\
\text { O'Reilly, 2018; Fritsch and Krabel, 2012; Hayter, } \\
\text { Lubynsky and Maroulis, 2017; Hayter et al., 2018; } \\
\text { Cunningham et al., 2016; Nilsson, Rickne and } \\
\text { Bengtsson, 2010; Bercovitz and Feldman, 2006) }\end{array}$ \\
\hline MANAGEMENT SCIENCE & 3 & $\begin{array}{l}\text { (Cohen, Nelson and Walsh, 2002; Gittelman and } \\
\text { Kogut, 2003; Zucker and Darby, 1996) }\end{array}$ \\
\hline R \& D MANAGEMENT & 2 & $\begin{array}{l}\text { (Bonaccorsi and Piccaluga, 1994; Cunningham, } \\
\text { Menter and O'Kane, 2018) }\end{array}$ \\
\hline TECHNOVATION & 2 & $\begin{array}{l}\text { (Chen, 1994; Kalar and Antoncic, 2015; } \\
\text { Vedovello, 1997) }\end{array}$ \\
\hline TECHNOLOGICAL FORECASTING AND SOCIAL & 17 & (Battaglia, Landoni and Rizzitelli, 2017; Perkmann \\
\hline CHANGE; INTERNATIONAL JOURNAL OF & & and Walsh, 2007; Poyago-Theotoky, Beath and \\
\hline MANAGEMENT REVIEWS; JOURNAL OF & & Siegel, 2002; Cockburn and Henderson, 1998; \\
\hline INDUSTRIAL ECONOMICS; SCIENCE AND & & Dutrénit, De Fuentes and Torres, 2010; Liyanage \\
\hline PUBLIC POLICY; JOURNAL OF KNOWLEDGE & & et al., 2009; Zander and Kogut, 1995; Grimpe and \\
\hline MANAGEMENT ORGANIZATION SCIENCE; & & Hussinger, 2008; Freitas and Verspagen, 2017; \\
\hline INDUSTRY AND INNOVATION; JOURNAL OF & & Zucker and Darby, 1996; Ankrah and Omar, 2015; \\
\hline EVOLUTIONARY ECONOMICS; PROCEEDINGS & & Wong and Radcliffe, 2000; Agrawal, 2006; Jensen \\
\hline OF THE NATIONAL ACADEMY OF SCIENCES & & and Thursby, 2001; Cummings and Teng, 2003; \\
\hline OF THE UNITED STATES OF AMERICA; & & Link, Siegel and Bozeman, 2007; Howells, 2002; \\
\hline SCANDINAVIAN JOURNAL OF & & Geuna and Muscio, 2009; Alavi and Leidner, \\
\hline MANAGEMENT; TECHNOLOGY ANALYSIS \& & & 2001) \\
\hline \multicolumn{3}{|l|}{ STRATEGIC MANAGEMENT; STRATEGIC } \\
\hline \multicolumn{3}{|l|}{ MANAGEMENT JOURNAL; INTERNATIONAL } \\
\hline \multicolumn{3}{|l|}{ JOURNAL OF INDUSTRIAL ORGANIZATION; } \\
\hline \multicolumn{3}{|l|}{ JOURNAL OF ENGINEERING AND } \\
\hline \multicolumn{3}{|l|}{ TECHNOLOGY MANAGEMENT; INDUSTRIAL } \\
\hline \multicolumn{3}{|l|}{ AND CORPORATE CHANGE; URBAN } \\
\hline \multicolumn{3}{|l|}{ STUDIES; MIS QUARTERLY } \\
\hline Section & $\begin{array}{l}\text { Total no. } \\
\text { of articles }\end{array}$ & Articles included in the section \\
\hline
\end{tabular}




\begin{tabular}{|c|c|c|}
\hline Types of transfer activities & 30 & $\begin{array}{l}\text { (Abreu and Grinevich, 2013; Owen-Smith and } \\
\text { Powell, 2003; Laursen and Salter, 2004; Kalar and } \\
\text { Antoncic, 2015; Fritsch and Krabel, 2012; Cohen, } \\
\text { Nelson and Walsh, 2002; Agrawal, 2006; Zucker } \\
\text { and Darby, 1996; Kenney and Patton, 2009; } \\
\text { Hayter et al., 2018; Hayter, Lubynsky and } \\
\text { Maroulis, 2017; Gittelman and Kogut, 2003; } \\
\text { Cunningham et al., 2016; Cunningham and } \\
\text { O'Reilly, 2018; Cunningham, Menter and O'Kane, } \\
\text { 2018; Zucker and Darby, 2006; Cockburn and } \\
\text { Henderson, 1998; Zander and Kogut, 1995; Wong } \\
\text { and Radcliffe, 2000; Liyanage et al.., 2009; Jensen } \\
\text { and Thursby, 2001; Howells, 2002; Freitas and } \\
\text { Verspagen, 2017; Cummings and Teng, 2003; } \\
\text { Cassiman, Di Guardo and Valentini, 2010; } \\
\text { Bekkers and Freitas, 2008; Alavi and Leidner, } \\
\text { 2001; Brescia, Colombo and Landoni, 2016; } \\
\text { Bercovitz and Feldman, 2006; Battaglia, Landoni } \\
\text { and Rizzitelli, 2017) } \\
\text { (Battistella, De Toni and Pillon, 2016; Dutrénit, } \\
\text { De Fuentes and Torres, 2010; Mowery and } \\
\text { Ziedonis, 2015; Link, Siegel and Bozeman, 2007; } \\
\text { Schartinger, Rammer and Fröhlich, 2006; Grimpe } \\
\text { and Hussinger, 2008; Perkmann and Walsh, } \\
\text { 2007; Chen, 1994; Ankrah and Omar, 2015; } \\
\text { Perkmann et al., 2013; Nilsson, Rickne and } \\
\text { Bengtsson, 2010; Bercovitz and Feldman, 2006) } \\
\text { (Baba, Shichijo and Sedita, 2009; D'Este and } \\
\text { Patel, 2007; Faulkner and Senker, 1994; } \\
\text { Bonaccorsi and Piccaluga, 1994) }\end{array}$ \\
\hline Both Sections & 4 & Bonaccorsi and Piccaluga, 1994) \\
\hline Total & 46 & \\
\hline
\end{tabular}

